\title{
DYNAMIC RESPONSE ANALYSIS ON THE INTERACTION BETWEEN FLEXIBLE BODIES OF LARGE-SIZED WIND TURBINE UNDER RANDOM WIND LOADS
}

\author{
Yilun Li \\ Sino-French Engineering School, Beijing \\ University of Aeronautics and Astronautics \\ Beijing 100191, China
}

\author{
Shuangxi Guo \\ a. AVIC Composite Corporation LTD, National \\ Key Laboratory of Advanced Composites \\ Beijing 100095, China \\ b. Key Laboratory of Mechanics in Fluid Solid \\ Coupling System, Institute of Mechanics, \\ Chinese Academy of Sciences \\ Beijing 100190, China
}

\author{
Min Li \\ School of Aeronautics Sciences \\ and Engineering, Beijing University \\ of Aeronautics and Astronautics \\ Beijing 100191, China \\ limin@buaa.edu.cn
}

\author{
Weimin Chen* \\ a. Key Laboratory of Mechanics in \\ Fluid Solid Coupling System, \\ Institute of Mechanics, Chinese \\ Academy of Sciences \\ Beijing 100190, China \\ b. School of Engineering Science, \\ University of Chinese Academy \\ of Sciences \\ Beijing 100049, China
}

\author{
Yue Kong \\ School of Aeronautics \\ Sciences and Engineering, \\ Beihang University \\ Beijing 100191, China
}

\begin{abstract}
As the output power of wind turbine increasingly gets larger, the structural flexibility of elastic bodies, such as rotor blades and tower, gets more significant owing to larger structural size. In that case, the dynamic interaction between these flexible bodies become more profound and may significantly impact the dynamic response of the whole wind turbine. In this study, the integrated model of a 5-MW wind turbine is developed based on the finite element simulations so as to carry out dynamic response analysis under random wind load, in terms of both time history and frequency spectrum, considering the interactions between the flexible bodies. And, the load evolution along its transmitting route and mechanical energy distribution during the dynamic response are examined. And, the influence of the stiffness and motion of the supporting tower on the integrated system is discussed.

The basic dynamic characteristics and responses of 3 models, i.e. the integrated wind turbine model, a simplified turbine model (blades, hub and nacelle are simplified as lumped
\end{abstract}

masses) and a rigid supported blade, are examined, and their results are compared in both time and frequency domains. Based on our numerical simulations, the dynamic coupling mechanism are explained in terms of the load transmission and energy consumption. It is found that the dynamic interaction between flexible bodies is profound for wind turbine with large structural size, e.g. the load and displacement of the tower top gets around $15 \%$ larger mainly due to the elastic deformation and dynamic behaviors (called inertial-elastic effect here) of the flexible blade; On the other hand, the elastic deformation may additionally consume around 10\% energy (called energyconsuming effect) coming from external wind load and consequently decreases the displacement of the tower. In other words, there is a competition between the energy-consuming effect and inertial-elastic effect of the flexible blade on the overall dynamic response of the wind turbine. And similarly, the displacement of the blade gets up to $20 \%$ larger because the elastic-dynamic behaviors of the tower principally provides a elastic and moving support which can significantly change the 
natural mode shape of the integrated wind turbine and decrease the natural frequency of the rotor blade.

Key Words: wind turbine; dynamic response; finite element simulation; coupling system; random wind

\section{INTRODUCTION}

Wind turbine is essentially an integrated system composes of multiple flexible bodies such as slender blades, tube tower and its supporting part, which may introduce elastic structure deformation, vibration and then static/dynamic interaction between these flexible bodies during the operation process and dynamic response under external wind load. For example, under action of wind load along with rotation motion of rotor, the blade may elastically deform and vibrate, and the vibration can propagate and develop upon the bottom elastic tower through the rotation axis of hub, which introduces additional structure stress and, even, changes the rotor's spatial position on the tower top. Then the distribution of rotor aerodynamic force may change consequently, and the deformation and vibration of the blades could be changed again in return. As the electricity power increasingly rises, the structural size gets larger too, e.g. up to a lever of, or more than, $100 \mathrm{~m}$ of tower height and/or rotor diameter. Consequently, the structural elasticity of blade and tower becomes more profound and the interaction between the flexible bodies can no longer be neglected. It is found that the tower elasticity can significantly influence the top blade deformation[1], and the shear stress caused by blade vibration can increase the tower displacement, even up to $300 \%$ [2]. Therefore, it is significant to consider the structural elasticity and the dynamic coupling effect of the flexible bodies for sake of an accurate and reliable strength/safety assessment during wind turbine operation process and dynamic response under wind load.

Mostly, some simplified models were used in previous researches on wind turbine strength and dynamic response. For examples, only a single tower was considered, where the other parts such as blade and nacelle are simplified as a centered mass, to calculate the tower dynamic characteristics, or similarly to the case of blade-only model. Adhikari[3] regarded the top rotor as a centered mass on the tower top and calculated the frequency and response of the tower. By using similar model, Negm[4] optimized the structural properties of an tower, and Bazeos[5] studied the static strength and anti-seismic performance of a steel tower. These researches provided necessary results for wind turbine design in practices, but it is noted that the elasticity, no mention the dynamic coupling effect, of the flexible bodies is somewhat simplified, or not all included, there.

Recently, in order to consider a multi-body coupling wind turbine, some researchers studied a single tower (or blade) by means of introducing proper boundary condition which is used to model the effect of other parts of the integrated wind turbine. Murtagh[6] considered the shear force coming from the turbine blades as an coupling force acting on the tower top during solving the tower dynamic equation to analyze the coupling of blade and tower, and further presented influence of harmonic mass-damper on wind turbine vibration[7]. Similarly, Chen[2] examined the coupling effects, the wind load and the tower response, he pointed out that if the blade shear force was included the tower displacement would increase by up to 2 times. Spagnoli[8] presented the dynamic response of two wind turbines and compared them with the results under static and uniform pressure. Based on dynamic equations of one-degree of freedom tower and flexible blade, Liu[9] presented the natural frequency of a blade-tower model, and he lumped the up turbine as a concentrated mass then gave the wind loads under consideration of tower first bending mode.

Further, some other researchers developed a mixed model which combines rigid body and flexible body together, and considered dynamic-flexible-behavior of other parts as a unidirectional effect instead of coupling effect. Lee[10] used the Floquet theory to solve out the eigenvalue of a rigid-flexiblebody based on the assumption of linear combination of steady solution. He gave the results of the frequency and modal shape of a two-blade wind turbine without dynamic response. Wang[1] also theoretically solved the multi-body equation, and pointed out the tower stiffness can significantly change the blade displacement. Kang [11] developed a coupled equation group of a blade-tower model to study the stability of wind turbine, and he found that at a certain mixed natural mode of blade-tower system it may be unstable. However, fewer dynamic response, let alone the interaction mechanism of different flexible parts, of the mixed system was reported.

In this study, the dynamic response, in terms of both time history and frequency spectrum, of a large-sized wind turbine is presented based on the developed finite element model of the integrated blade-tower system so as to consider the elastic deformation and dynamic interactions of the flexible bodies like the blade and tower. In order to have a deeper insight into the mechanism and impact of the elastically dynamic interaction, the load evolution along its transmitting route and mechanical energy distribution during the whole dynamic response under random wind load are studied and compared, for cases of three different model. At last, the influence of the stiffness and motion of the supporting tower on the overall integrated system response is discussed based on the theoretical analysis of the supporting base properties.

\section{THE NATURAL DYNAMIC CHARACTERISTICS OF THE INTEGRATED WIND TURBINE \\ 2.1 The FEM Models}

In order to have a deeper insight on the impact of the component interaction on the dynamic response, we built 3 FEM models as shown in Fig.1, i.e. Model 1, the integrated wind turbine model including three flexible blades and a tower on the top of which hub and nacelle are simplified as lumped mass; Model 2, the simplified flexible tower-only model where the other parts like the blades, hub and nacelle are simplified as lumped mass, and the tower bottom end is fixed; Model 3, the simplified blade-only model of which roots are fixed on the top of the rigid tower as a cantilever beam. In our FEM models, every blade was uniformly divided into 123 Euler beam elements, and the tower was divided into 100 beam elements. 


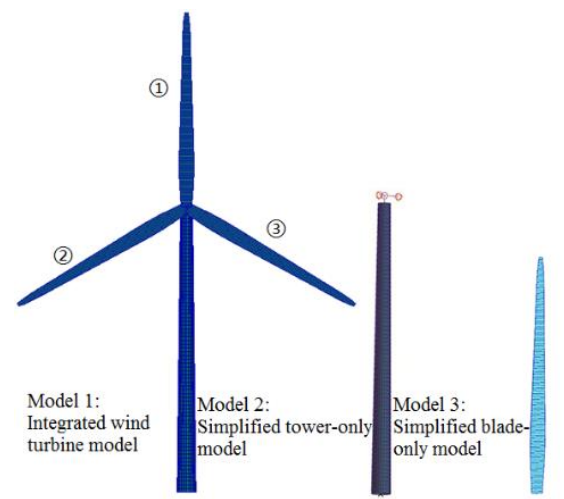

FIGURE 1. THE INTEGRATED WIND TURBINE AND THE SIMPLIFIED TOWER-ONLY AND BLADE-ONLY MODELS

We use the structure parameters of a 5-MW wind turbine developed by the NREL (National Renewable Energy Laboratory) of the U.S. as our example model. The tube tower height is $87.6 \mathrm{~m}$. The values of the diameter and thickness of the tower lineally changing from the bottom, $6 \mathrm{~m}$ and $35.1 \mathrm{~mm}$, to the top, $3.87 \mathrm{~m}$ and $24.7 \mathrm{~mm}[12]$ respectively. And the other geometrical and material parameters are listed in Table 1 where the blade's details is from LMH64-5[13] and the structural damping is $0.01[12]$.

TABLE 1. THE MAIN PARAMETERS OF THE WIND TERBINE

\begin{tabular}{cc}
\hline Parameters & Value \\
\hline Blade number & 3 \\
Rotor, Hub Diameter & $126 \mathrm{~m}, 3 \mathrm{~m}$ \\
Hub height & $90 \mathrm{~m}$ \\
Rated wind speed & $11.4 \mathrm{~m} / \mathrm{s}$, \\
Rated rotor speed & $12.1 \mathrm{r} / \mathrm{min}$ \\
Rotor whole mass & $110000 \mathrm{~kg}$ \\
Nacelle whole mass & $240000 \mathrm{~kg}$ \\
Tower mass density & $8500 \mathrm{~kg} / \mathrm{m}^{3}$ \\
Tower elastic modules & $210 \mathrm{GPa}$ \\
Tower shear modules & $80.8 \mathrm{GPa}$ \\
Blade length & $61.5 \mathrm{~m}$ \\
Blade elastic modules & $14.8 \mathrm{GPa}$ \\
Blade mass density & $1700 \mathrm{~kg} / \mathrm{m}^{3}$ \\
\hline
\end{tabular}

\subsection{The Natural Dynamic Characteristics of the Integrated Wind Turbine}

Structure vibration often happens under operation condition that various environmental load and body forces such as dynamic wind load and structural gravity force and rotor's centrifugal force may significantly act on the whole wind turbine. Particularly, when the frequency of the external load is coincident with the structural frequency, resonance with large amplitude will happen, which may induce the structure fatigue life and, even, directly result in body damage. So the analysis of natural dynamic characteristics is the basic design work so that the natural frequency is different from the external load as far as possible to avoid resonance. Here we calculate the natural frequency of the wind turbine including both flexible blades and tower, and the results are compared with that given by Jonkman[12], and the frequencies of the first three along-wind tower bending modes(the mode 1,5 and 6) are also listed and

compared with the simplified tower model in Table 2. Satisfied agreement between our numerical and Jonkman's results, i.e. less than $5 \%$ differences, is seen.

A little difference is seen, i.e. the first bending frequency of the blade-tower model is a little smaller than the tower-only model while the other frequencies of modes with higher order number are slightly higher. The reason of that difference might be for the first bending mode, the blade deformation plus tower deformation makes up the modal shape, as if the length of the beam gets larger, so the overall flexibility is smaller than the case of tower-only. While for the higher-order bending modes, the modal shapes become more complicated and higher-order deformation of the blades may increase the modal stiffness of the blade-tower system, that may increase the modal frequency.

\begin{tabular}{ccccc}
\multicolumn{5}{c}{ TABLE 2. NATURAL FREQUENCIES OF DIFFERENT MODELS } \\
\hline Mode & $\begin{array}{c}\text { Integrated } \\
\text { Turbine } \\
/ \mathrm{Hz}\end{array}$ & $\begin{array}{c}\text { Simplified } \\
\text { Turbine } \\
/ \mathrm{Hz}\end{array}$ & $\begin{array}{c}\text { Res[12] } \\
/ \mathrm{Hz}\end{array}$ & $\begin{array}{c}\text { Difference } \\
/ \%\end{array}$ \\
$\begin{array}{c}\text { 1st tower fore-aft } \\
\text { 1 st blade }\end{array}$ & 0.311 & 0.315 & 0.320 & 2.9 \\
Asymmetric & 0.659 & $/$ & 0.630 & 4.4 \\
$\begin{array}{c}\text { Flapwise yaw } \\
\text { 1st blade }\end{array}$ & & & & \\
Asymmetric & 0.689 & $/$ & 0.669 & 2.9 \\
$\begin{array}{c}\text { Flapwise pitch } \\
\text { 1st blade }\end{array}$ & & & & \\
Symmetric & 0.722 & $/$ & 0.702 & 2.8 \\
Flapwise pitch & & & & \\
2nd tower fore-aft & 2.819 & 2.712 & $/$ & $/$ \\
3rd tower fore-aft & 7.279 & 7.198 & $/$ & $/$
\end{tabular}

Additionally, the selected modal shape are presented in Fig.2. It is noted that the modal shape of the blade-tower model is somewhat different from the simplified models. Compared with either the individual tower-only or the blade-only model, there are some additional and/or different modes. For examples, the rotor mode in Fig. 2a presents a leading-lag-still modal shape which would not occur to the simplified three-blade model, and the blade flapping modes, symmetric and anti-symmetric in Fig.2c and d, present different modes from the blade-only model.

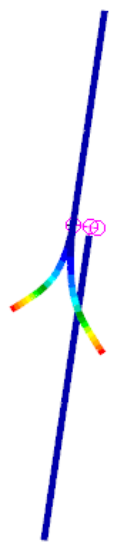

(a)

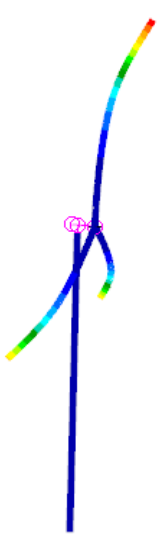

(b) 


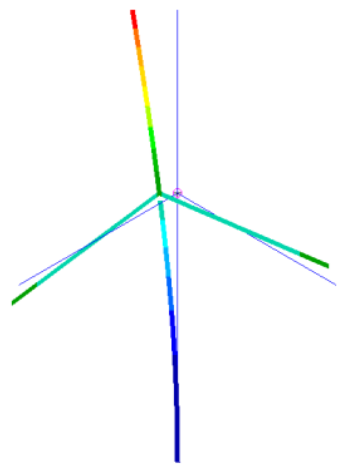

(c)

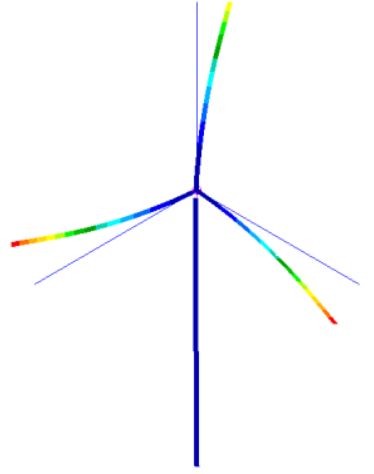

(d)
FIGURE 2. THE SELECTED MODAL SHAPES OF THE INTEGRATED WIND TURBINE (a) 1st BLADE ASYMMETRIC FLAPWISE YAW (b) 1st BLADE ASYMMETRIC FLAPWISE PITCH (c) 1st TOWER SIDE-TO-SIDE (d) 1st BLADE SYMMETRIC EDGEWISE

Additionally, there are some blade-tower-coupling modes, e.g. modes in Fig. $2 \mathrm{a}$ and $\mathrm{b}$, of which coupled modal shape indicate the interaction between the blade deformation and tower deformation. So we may say, the modal shape of the blade-towercoupling system is more complicated, and there are additional and different modes.

\section{THE DYNAMIC RESPONSE UNDER RANDOM WIND}

The structural displacement and stress of Model 1 are calculated under random wind loads and compared with the two simplified models, Model 2 and 3 respectively, during the dynamic response. As we know, in practices, the wind speed is usually present somewhat randomness, and there is a temporalspatial correlation of wind speed distribution. Firstly, among the popular wind spectrums such as Harris spectrum, Kaimal spectrum and DNV and IEC61400 criteria, we choose the mostly used Kaimal spectrum[14] to calculate an time history approximation of wind speed and consequent wind load. The wind speed spectrum is:

$$
P S D(f)=\frac{I^{2} V_{10 \min } l}{\left(1+1.5 \frac{f l}{V_{10 \min }}\right)^{5 / 3}}
$$

where $I$ is the turbulence intensity. $V_{10 \min }$ is the average wind speed in ten minutes at the given point. $l$ is the scalar taking values as $l=20 h$ when the height $h<30 m$ and $l=600 h$ when $h \geq 30 \mathrm{~m}$. $f$ is the wind frequency. If we take the average wind speed $V_{10 \mathrm{~min}}=11.4 \mathrm{~m} / \mathrm{s}, I=0.1$ and the time step $0.02 \mathrm{~s}$, the time history of wind speed at the tower top height $(90 \mathrm{~m})$ among 200s time duration is plotted in Fig.3. Then for a slender body, the drag force of wind can be given by the empirical expression[6] as

$$
F(t)=\frac{1}{2} C_{D} \rho A v^{2}(t)
$$

where $C_{D}$ is the drag coefficient, and its value is 2.0 here. $\rho$ is the air density having the value $1.25 \mathrm{~kg} / \mathrm{m} 3 . A$ is the windward area of the blade, and $v(t)$ is the instant wind speed. Then the mode superposition method is used to solve out the dynamic response under the wind load shown in Eq.(2).

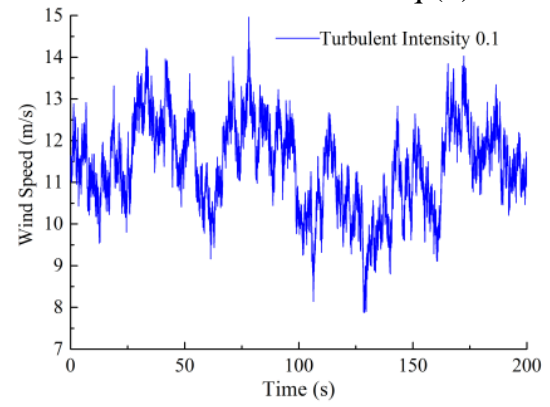

FIGURE 3. THE WIND SPEED AT THE HUB HEIGHT

As we know, the wind speed change little as the height increases. It is assumed that the wind load is uniformly acting on every blade, and the value of wind speed is the same with that at the hub height. Here, only the vibration in the blade pitch direction is considered, so only the wind load in the direction vertical to the rotor plan is calculated. In addition, regarding the special dynamic behavior of the rotor blade, the body forces such as the centrifugal and gravity forces of the blades are considered as continuously distributing along the blade span respectively in two directions so as to model the effects coming from rotor rotation.

\subsection{The Influence of Elastic Tower on the Blade Dynamic Response}

For the blades of the integrated model and simplified model respectively, their base stiffness are essentially different, i.e. the former blade is actually supported on the top of the flexible tower which may deform, vibrate and, even, interact with the top blade, while the later one is just fixed at its root.

The selected displacements of blade tip are presented in Fig. 4 in terms of spectrum curves, where blade 1 and blade 2 are chosen to indicate the different gravity effects owing to their different spatial positions as shown in Fig.1. Generally speaking, comparing the curves of different model, there obvious differences can be seen in terms of the number, amplitude and frequency values of the spectrum peaks. There are more peaks for the response of the integrated model, which are at the additional frequencies of the coupled system such as the tower pitch and higher-order combined blade modes, compared to the tower or blade only model.

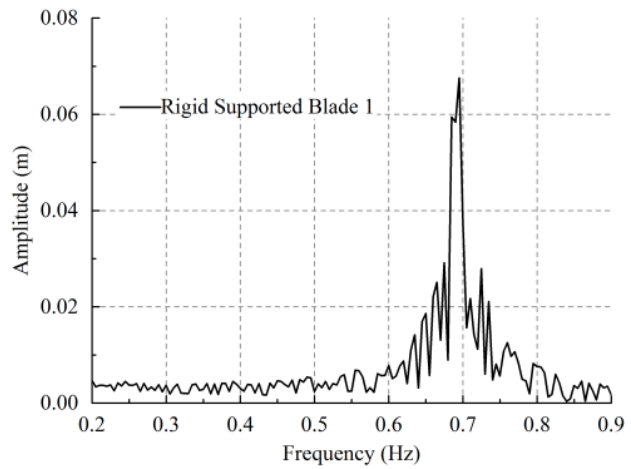

(a) 


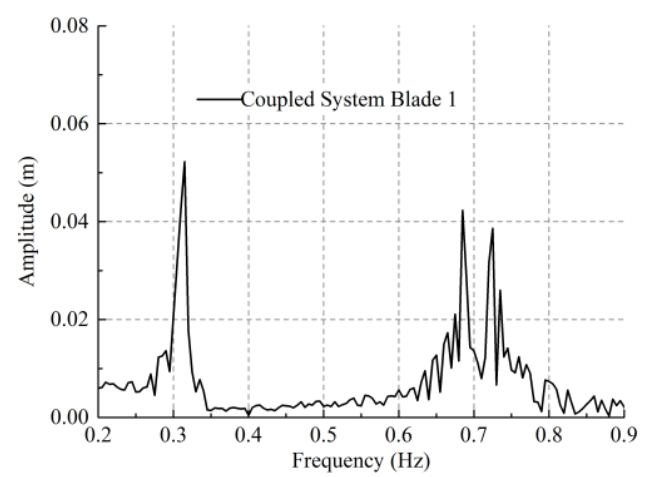

(b)

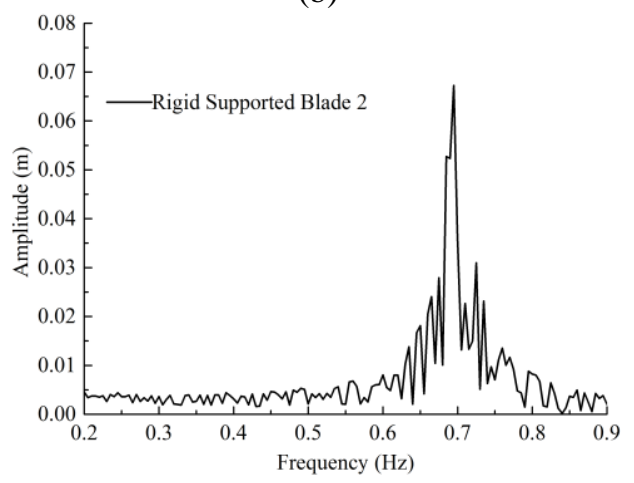

(c)

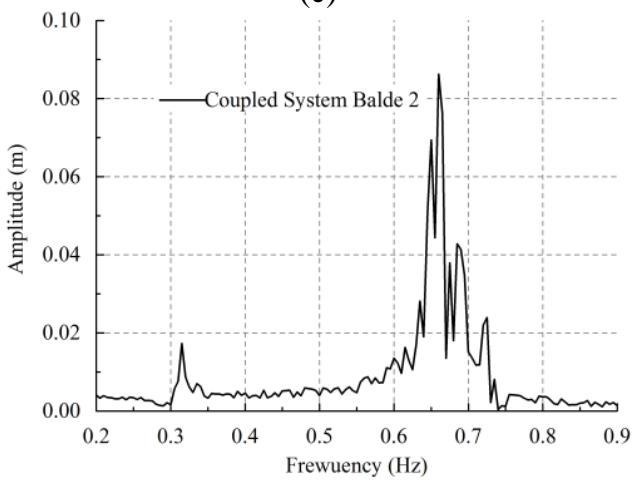

(d)

FIGURE 4. DISPLACEMENT FREQUENCY SPECTRUMS FOR BLADES OF DIFFERENT MODELS (a) THE RIGID SUPPORTED BLADE 1 (b) BLADE 1 OF THE INTEGRATED SYSTEM (c) THE RIGID SUPPORTED BLADE 2 (d) BLADE 2 OF THE INTEGRATED SYSTEM

Comparing the Fig. $4 \mathrm{c}$ and $4 \mathrm{~d}$, we can see that the displacement amplitude of the integrated model rises by around $20 \%$, or the tower deformation and vibration may amplify its top blade response. And, comparing the Fig. $4 \mathrm{~b}$ and $4 \mathrm{~d}$, it is seen that since the modal shape of different blade changes, the displacement amplitude of different blades changes too. It is also noted that the maximum amplitude happens at different frequencies, i.e. at $0.311 \mathrm{~Hz}$ for blade 1 while at $0.677 \mathrm{~Hz}$ for blade 2. Because $0.311 \mathrm{~Hz}$ and $0.677 \mathrm{~Hz}$ are respectively corresponds to the mode where the blade has the maximum modal shape deformation.

The maximum bending stress of the three blades, listed in Table 3, shows that it significantly depends on the blade's azimuth (ot the rotation position). More specifically, the root stress of blade 1 drops by $7.18 \%$ while blade 2 rises by $10.63 \%$ respectively, compared to the blade-only model. That's in part because of the anti-symmetrical flapping modes of the integrated tower-blade model, which makes the blades at different position may change a lot.

\begin{tabular}{cc}
\multicolumn{2}{c}{ TABLE 3. MAXIMUM STRESS OF THE BLADES } \\
\hline Component & Stress/MPa \\
\hline Rigid Supportted Blade1 & 6.82 \\
Blade 1 in Integrated Turbine & 6.33 \\
Rigid Supportted Blade 2 & 6.68 \\
Blade 2 in Integrated Turbine & 7.39
\end{tabular}

\subsection{The Influence of Elastic Blades on the Tower Dynamic Response}

The spectrum curve of tower top displacement, presented in Fig. 5, shows that the peak value of the integrated model drops to nearly one-third of the tower-only model while its peak position at the first tower bending frequency. To the tower response of the first bending mode, because the blade elastic deformation, actually accounting for a profound part of the overall system deformation, can consume a part of the energy coming from the wind, the tower deformation consequently get smaller. That could be further proved through comparing the time histories of tower top displacement in Fig. 6. The tower maximum bending stress of the integrated models drops from $29.8 \mathrm{MPa}$ of the simplified model to $10.1 \mathrm{MPa}$. That is to say the tower stress may be overestimated by the simplified model, by up to $66.11 \%$.

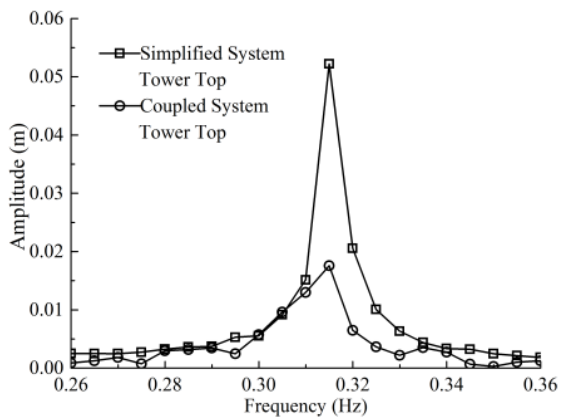

FIGURE 5. FREQUENCY SPECTRUM OF THE DISPLACEMENT AT TOWER TOP

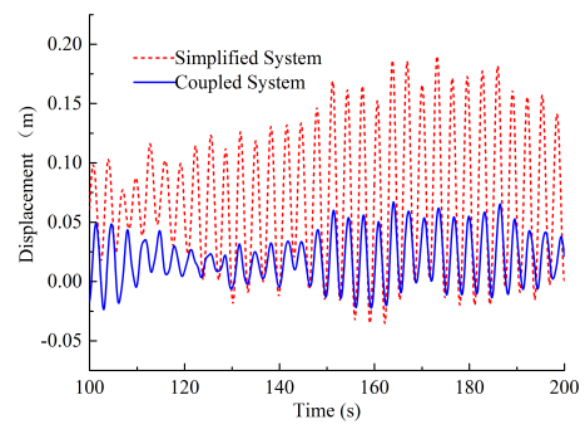

FIGURE 6. TIME HISTORY OF THE DISPLACEMENT AT TOWER TOP 


\section{DISCUSSION ON THE COUPLING MECHANISM OF ELASTIC BLADE AND TOWER DURING DYNAMIC RESPONSE}

The displacement spectrum curves of tower top in Fig.7a indicate that under the consideration of the dynamic interaction between the elastic blade and tower, not only the peak value of the displacement amplitude may change but also there exist an offset of the frequency corresponding to the displacement peak. And it is worthwhile to point out that the random wind load actually changes with its frequency, owing to its dependence on the phase angle and the nonlinear relationship between the wind load and the velocity (Eq.(2)), the spectrum of wind load acting on per unit area of the structure is shown in Fig.7b. So we should distinct the response differences respectively owing to the external wind load at different frequencies and structural dynamic coupling of flexible bodies.

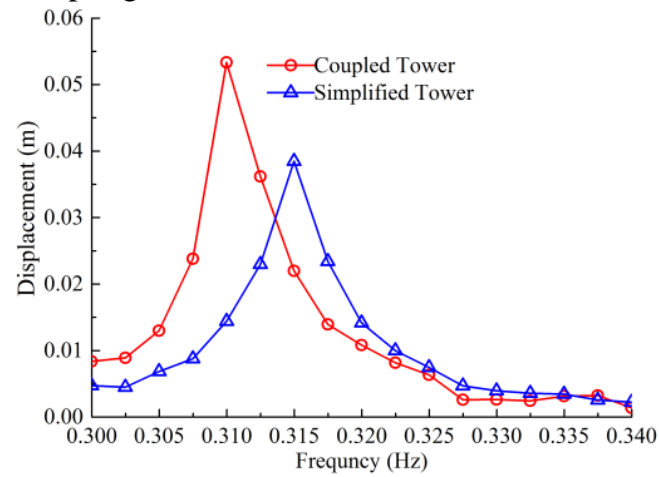

(a)

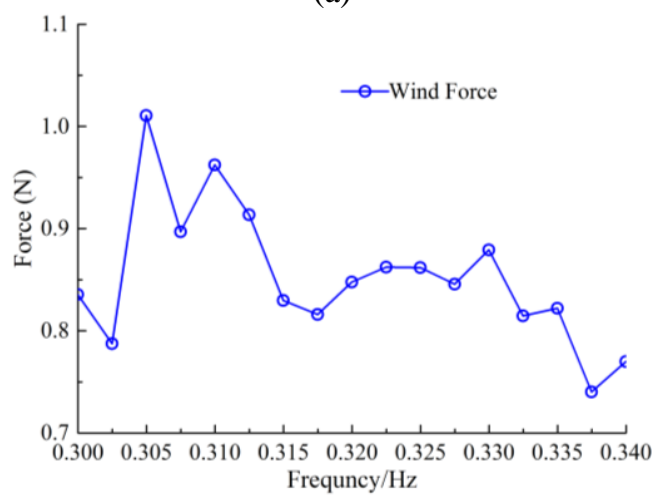

(b)

FIGURE 7. FREQUENCY SPECTRUM OF THE TOWER TOP RESPONSE (a) THE DISPLACEMENT SPECTRUM (b) THE WIND LOAD SPECTRUM

\subsection{Tower Stress Increase Caused by the Top Blade's Deformation and Vibration}

In order to examine the effect of flexible blade on the tower response, two wind load cases are considered to the integrated model, i.e. Case 1 the wind load is uniformly distributed on the three blades and Case 2 the wind load is concentrated on the tower top directly, see Fig.8. And, the dynamic response of the simplified tower-only model (Case 3 ) is given as comparison so as to have a deeper insight into the blade-tower coupling mechanism.

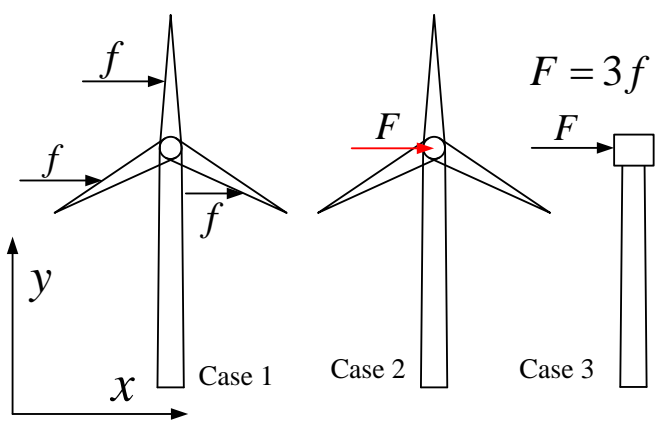

FIGURE 8. THE CASES OF WIND LOAD ACTING ON COUPLED AND SIMPLIFIED WIND TURBINE MODELS

The displacement spectrum curves of the tower top, ranging from $0.0 \mathrm{~Hz}$ to $3.0 \mathrm{~Hz}$ and presented in Fig. 9, show that the maximum displacement amplitude happens at the first bending frequency. Then, particularlly, the local spectrum, ranging from $0.28 \mathrm{~Hz}$ to $0.34 \mathrm{~Hz}$, is presented in Fig. $9 \mathrm{~b}$, it is seen that the displacement amplitude rises by $15.0 \%$ and the bending frequency drops a little principally owing to the larger body length and lower bending stiffness of the blade-tower model than the simplified tower-only model. Additionally, the wind load spectrum, presented in Fig.10, shows that the wind load at the first bending frequency gets $14.0 \%$ larger than the simplified model.

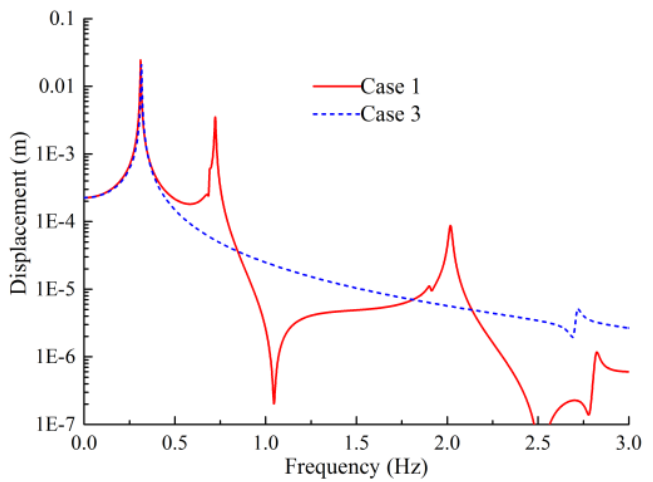

(a)

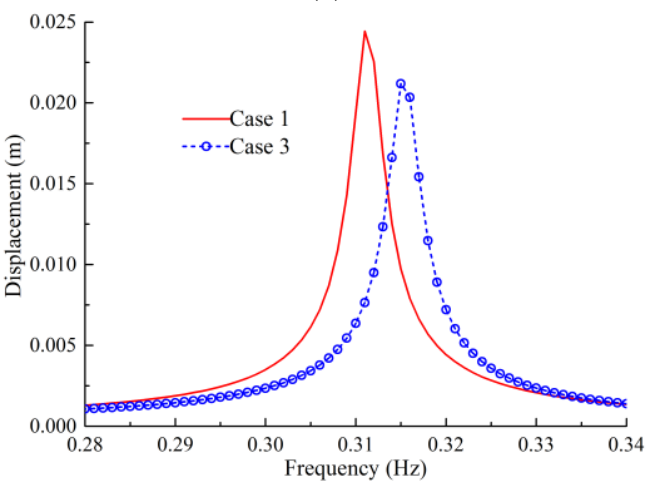

(b)

FIGURE 9. COMPARISON OF THE FREQUENCY DOMAIN RESPONSE OF DIFFERENT MODELS (a) THE DISPLACEMENT SPECTRUM (b) THE DISPLACEMENT SPECTRUM AT TOWER BENDING FREQUENCY

In order to examine the reason why the wind load, running through the flexible blade to the tower top, gets larger, for clarity 
and simplicity, here we take an one-freedom-degree system as an example to give its theoretical explanation. The governing equation of the one-freedom-degree system can be written as

$$
m \ddot{y}+c \dot{y}+k y=F_{0} \sin (\omega t)
$$

The base force is

$$
F_{\text {sup }}=\sqrt{(k y)^{2}+(c \dot{y})^{2}}
$$

So the force amplitude ratio $\bar{F}$ of the base force $F_{\text {sup }}$ to the external load $F_{0}$ is

$$
\bar{F}=\frac{F_{\text {sup }}}{F_{0}}=\sqrt{\frac{1+(2 \xi \lambda)^{2}}{\left(1-\lambda^{2}\right)^{2}+(2 \xi \lambda)^{2}}}
$$

where $\xi$ is the structural damping ratio. $\lambda$ is the frequency ratio of the external force to the natural structure. Then we have the plots of the force amplitude ratio $\bar{F}$ versus the frequency ratio $\lambda$ at different damping ratio $\xi$ as shown in Fig.11, called the load evolution along its transmitting route. It is noted that the value of force amplitude ratio $\bar{F}$ is larger than 1.0 , or the base force $F_{\text {sup }}$ is larger than the external load $F_{0}$, until the frequency ratio is larger than 1.42. As for our blade-tower system, the tower first bending frequency is smaller than the blade first frequency (it means the frequency ratio is smaller than 1.0 when the external load frequency is same with the tower first bending frequency), so the external wind force acting on the blade originally would be amplified as it runs through a flexible body, i.e. the blades.

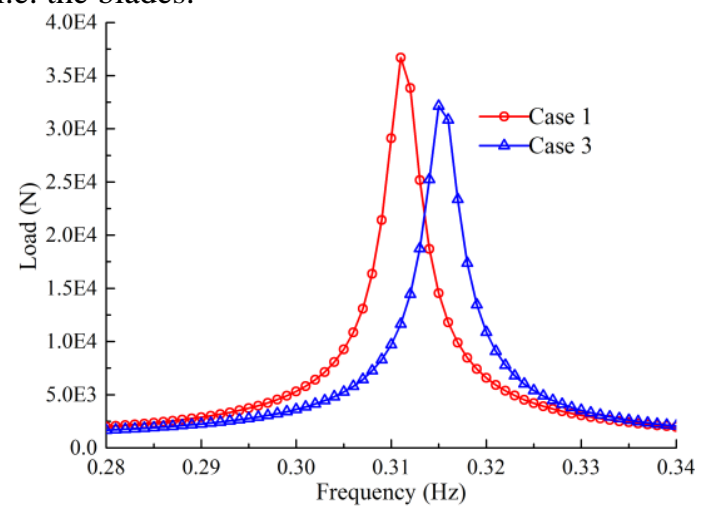

FIGURE 10. COMPARISON OF THE WIND LOAD AT THE TOWER TOP FOR CASE 1 AND CASE 3

If comparing the tower top displacements of case 2 and 3 where same wind loads are acting at the tower top directly, or without the load amplification effect of the flexible blade, we can see that the tower displacement gets a little smaller(Fig. 12). The mechanical energy distribution of the system's different parts. i.e. the three blades and tower, is plotted in Fig. 13. It is shown that the response is mainly dominated by the tower bending while the energy consumed by the blade deformation and vibration is much less than that of the tower, just around 1/8 of the tower. That gives the reason why the tower displacement gets just a little smaller, though the flexible blades do consume certain energy during the dynamic response.

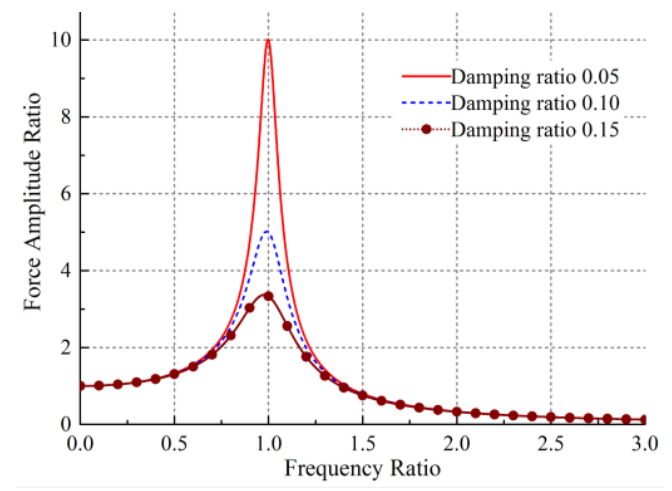

FIGURE 11. THE FORCE AMPLITUDE RATIO VERSUS FREQUENCY AT DIFFERENT DAMPING RATIO

By now, based on above results of the influences of dynamic and flexible behavior of top blade on tower response, we may say there are two influences: on one hand, wind load running through the flexible blades to the tower may be amplified, and consequently tower response gets larger up to $15.7 \%$ due to the elastic deformation and dynamic movement (called inertialelastic effect here) of the flexible blade; on the other hand, the tower response drops just a little because the elastic deformation of blade can consume some mechanical energy (called energyconsuming effect), around $10 \%$ of the tower. In other words, there is a competition between the energy-consuming effect and inertial-elastic effect of the flexible blade on the overall dynamic response of the wind turbine.

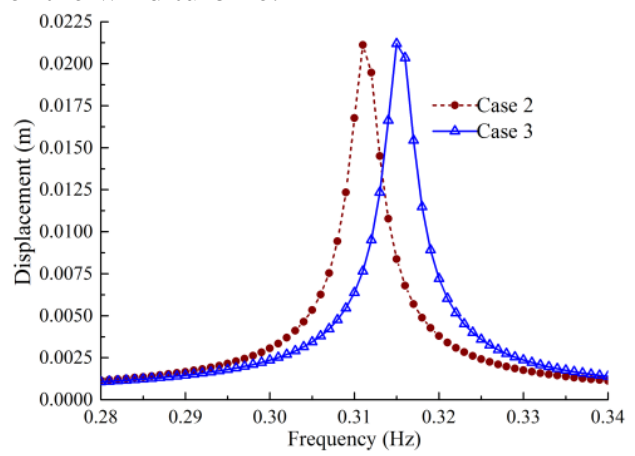

FIGURE 12. THE SPECTRUM OF DISPLACEMENT AT TOWER TOP OF CASE 2 AND CASE 3

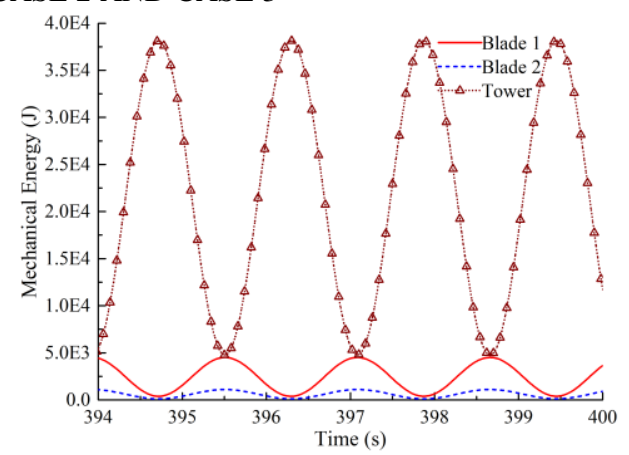

FIGURE 13. MECHANICAL ENERGY DISTRIBUTION OF DIFFERENT PARTS OF THE WIND TURBINE

\subsection{Blade Displacement Increase Caused by the Elastic Tower}


For the blade, two supporting cases, i.e. supported on the top of the flexible tower (Case 1 in Fig. 8) and fixed at the blade root as a cantilever beam (called Blade 4), are considered here, see Fig.14.

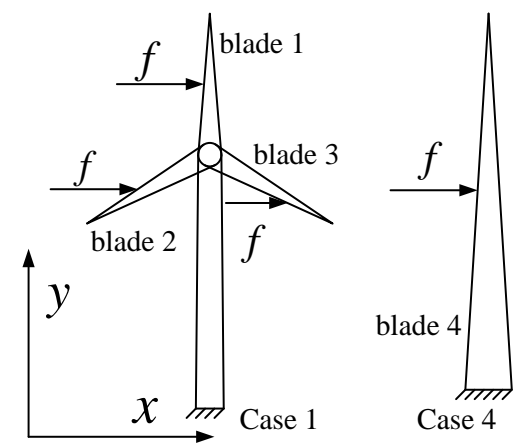

FIGURE 14. TWO SUPPORTING CASES OF BLADES (CASE 1 AND BLADE 4)

Blade tip displacement is plotted in terms of spectrum curve in Fig.15, and we can see, for case 1, there is an additional peak at lower frequency (corresponding to the tower first bending frequency), and the maximum blade displacement of blade 1 gets a little larger while the diaplcement peak of blade 2 gets smaller than blade 4. Regarding that the blade tip displacement is made of responses coming the tower bending and the elastic deformation of its own, the elastic deformation of blade 1 and 4 are compared in Fig.15b. Then we may see the elastic deformation and consequently the elastic potential energy of the blade 1 rise by $16.7 \%$ due to the supporting base of the flexible tower.

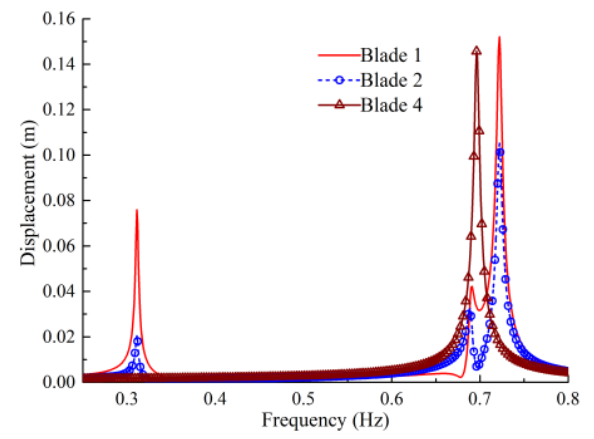

(a)

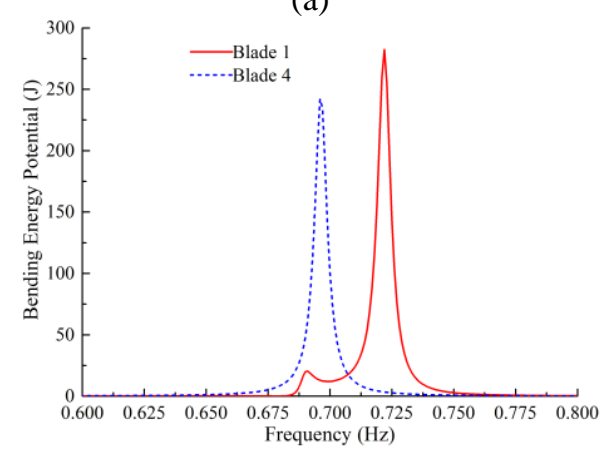

(b)

FIGURE 15. DISPLACEMENT AND ENERGY RESPONSE IN THE FREQUENCY DOMAIN (a) THE DISPLACEMENT RESPONSE (b) BLADE BENDING ENERGY POTENTIAL

The displacement difference between blade 1 and blade 2 in
Fig. 15 mainly because the for the anti-symmetric flapping mode the two blade has different modal shape (or displacement) as shown in Fig.16. It means that the blade response is also influenced by its azimuth. Actually, for a integrated wind turbine system, the blades with different azimuth have different modal shapes for a certain mode, so their dynamic response are different.

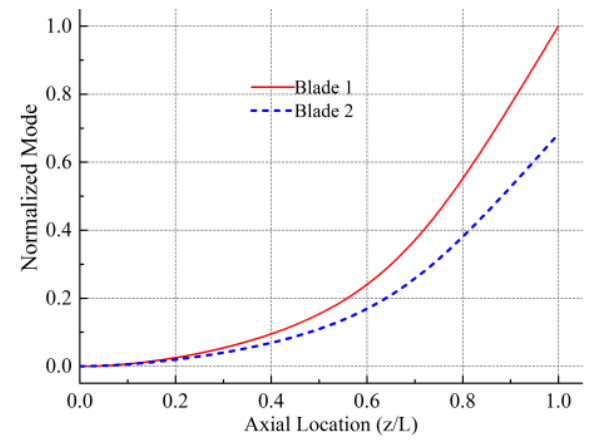

FIGURE 16. NORMALIZED MODAL SHAPES OF BLADES WITH DIFFERENT AZIMUTHS

Based on above results we see that because of bottom flexible tower the blade response may get larger. Here we would study this phenomenon and its mechanism by means of theoretically solving the dynamic response of a cantilever beam having elastic supporting base at its root by two springs, i.e. a translation spring $k_{1}$ and a rotation spring $k_{2}$. The governing equation of the beam is

$$
\rho A \frac{\partial^{2} w}{\partial t^{2}}+E I \frac{\partial^{4} w}{\partial x^{4}}+c \frac{\partial w}{\partial t}=f(x) \sin \omega t
$$

Based on the mode superposition method, the response is

$$
w(x, t)=\frac{f_{n} X_{n}(x)}{2 \xi_{n} \omega_{n}^{2}} \sin \left(\omega_{n} t+\theta\right)
$$

where $\omega_{n}$ is the beam natural frequency, and $X_{n}(x)$ is the natural modal shape and can be generally expressed as

$$
X(x)=a 1 \cos s x+a 2 \sin s x+a 3 \cosh s x+a 4 \sinh s x
$$

and

$$
s^{4}=(\rho A / E I) \omega^{2}
$$

The values of the coefficients in Eq. (8) can be determined by boundary conditions. For example, for a beam with a fixed left end and a free right end, we have

$$
a 1=1
$$

$$
\begin{gathered}
a 2=\frac{A B(\cos s L-\cosh s L)+2 A(\sinh s L+\sin s L)+(\cos s L+\cosh s L-2 B \sin s L)}{2 A(\cosh s L-B \sin s L)+(A B-1)(\sinh s L+\sin s L)} \\
a 3=\frac{2 A(\cos s L-B \sin s L)+(A B+1)(\sinh s L+\sin s L)}{2 A(\cosh s L-B \sin s L)+(A B-1)(\sinh s L+\sin s L)} \\
a 4=\frac{A B(\cos s L-\cosh s L)-(\cos s L+\cosh s L-2 B \sin s L)}{2 A(\cosh s L-B \sin s L)+(A B-1)(\sinh s L+\sin s L)}
\end{gathered}
$$

where $A=E I s^{3} / k_{1}$ and $B=E I s / k_{2}$. Now, we have the dispersion equation as

$$
\begin{aligned}
& A B(\cos s L \cosh s L-1)+(A+B) \cosh s L \sin s L+ \\
& (A-B) \cos s L \sinh s L-1-\cos s L \cosh s L=0
\end{aligned}
$$

to get the frequency of the beam. To compare the responses of the beam respectively with and without elastic supporting base, 
the displacement distribution along the beam length is given as

$$
\bar{A}(x)=\frac{f_{n} X_{n}(x)}{\omega_{n}^{2}}
$$

The example of the displacement amplitude distributing along the beam length is presented in Fig. 17 where the beam has different values of rotation stiffness (listed in Table 4). The beam's parameters are listed in Table 5 and has a $1.452 \mathrm{~Hz}$ natural frequency as its left end is fixed.

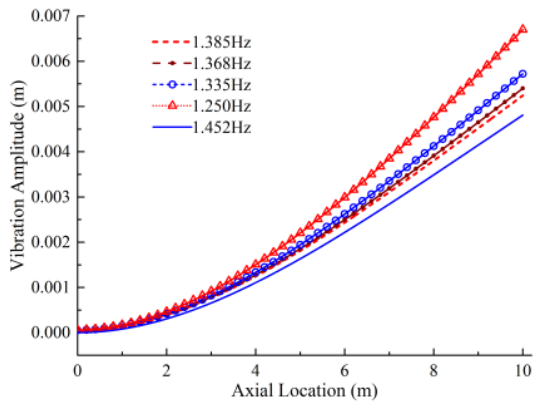

FIGURE 17. DISPLACEMENT AMPLITUDE ALONG BEAM LENGTH (BASED ON Eq.(12))

The displacement amplitude rises and the natural frequency drops as the rotational stiffness decreases because of the elastic supporting base, e.g. the displacement at right end rises by $8.3 \%$ $39.6 \%$ compared with the traditionally fixed beam. So we may say the elastic supporting base have two effects to the beam, one effect is that it can change the natural frequency and another effect is that it changes the dynamic response directly.

\begin{tabular}{ccc} 
TABLE 4. COEFFICIENTS OF THE ROTATION SPRING \\
$\begin{array}{c}\text { Translation } \\
\text { stiffness }\end{array}$ & $\begin{array}{c}\text { Rotation } \\
\text { stiffness }\end{array}$ & $\begin{array}{c}\text { Natural } \\
\text { frequency } / \mathrm{Hz}\end{array}$ \\
\hline $8 \mathrm{e} 6 \mathrm{~N} / \mathrm{m}$ & $8 \mathrm{e} 7 \mathrm{Nm} / \mathrm{rads}$ & 1.385 \\
$8 \mathrm{e} 6 \mathrm{~N} / \mathrm{m}$ & $6 \mathrm{e} 7 \mathrm{Nm} / \mathrm{rads}$ & 1.368 \\
$8 \mathrm{e} 6 \mathrm{~N} / \mathrm{m}$ & $4 \mathrm{e} 7 \mathrm{Nm} / \mathrm{rads}$ & 1.335 \\
$8 \mathrm{e} 6 \mathrm{~N} / \mathrm{m}$ & $2 \mathrm{e} 7 \mathrm{Nm} / \mathrm{rads}$ & 1.250 \\
\hline
\end{tabular}

\begin{tabular}{cc} 
TABLE 5. PARAMETERS OF THE CANTILEVER BEAM \\
\hline Parameter & Value \\
\hline Young's Modulus & $210 \mathrm{GPa}$ \\
Poisson ratio & 0.3 \\
Mass density & $7800 \mathrm{~kg} / \mathrm{m}^{3}$ \\
Diameter & $0.2 \mathrm{~m}$ \\
Length & $10 \mathrm{~m}$ \\
Translation stiffness & $8 \mathrm{e} 6 \mathrm{~N} / \mathrm{m}$ \\
Rotation stiffness & $8 \mathrm{e} 7 \mathrm{Nm} / \mathrm{rads}$ \\
\hline
\end{tabular}

\section{CONCLUSION}

The integrated blade-tower model of a 5-MW wind turbine is developed based on finite element simulations so as to carry out dynamic response analysis, in terms of both time history and frequency spectrum, of the large-sized wind turbine under consideration of the elastic bodies and their dynamic interactions. In order to have a deeper insight on the impact and mechanism of the dynamic interaction between the flexible tower and blades, the load transmitting route, mechanical energy distribution during the dynamic response under random wind load are studied. The basic dynamic characteristics and responses of different models, i.e. the integrated wind turbine model, the simplified tower model and blade model, are examined and it is found that the dynamic interaction between elastic bodies may significantly influence the dynamic analysis of the wind turbine. Based on our numerical simulations, we have following remarks:

1) The tower top displacement is around $15 \%$ larger than that of the simplified model mainly due to the elastic deformation and dynamic behavior of the flexible blade; On the other hand, the elastic deformation may additionally consume around $10 \%$ energy coming from the external wind load and consequently decreases the displacement of the tower. In other words, there is a competition between the energy-consuming effect and inertialelastic effect of the flexible blade on the overall dynamic response of the wind turbine.

2) The blade displacement gets up to $20 \%$ larger than that without blade-tower interaction, because the elastic-dynamic behaviors of the tower principally provides a more flexible and vibrating supporting base which can significantly change the natural mode shape of the integrated tower-blade system and can decrease the natural frequency of the top blade. Additionally, it is noted that the blade displacement actually change with the blade azimuths, even drops at certain azimuths, owing to the change of natural modal shape of the integrated wind turbine.

\section{ACKNOWLEDGMENTS}

The authors of this paper would like to thank the financial supports provided by the National Natural Sciences Foundation (Grant No. 11372320 and 11232012).

\section{REFERENCES}

[1] Wang J, Qin D, Lim T C. Dynamic analysis of horizontal axis wind turbine by thin-walled beam theory[J]. Journal of Sound and Vibration. 2010, 329(17): 3565-3586.

[2] Chen X, Li J, Chen J. Wind-induced response analysis of a wind turbine tower including the blade-tower coupling effect[J]. Journal of Zhejiang University SCIENCE A. 2009, 10(11): 1573-1580.

[3] Adhikari S, Bhattacharya S. Dynamic analysis of wind turbine towers on flexible foundations[J]. Shock and Vibration. 2012(19): 37-56.

[4] Negm H M, Maalawi K Y. Structural design optimization of wind turbine towers[J]. Computers and Structures. 2000, 74(6): 649-666.

[5] Bazeos N, Hatzigeorgiou G D, Hondros I D, et al. Static, seismic and stability analyses of a prototype wind turbine steel tower[J]. Engineering Structures. 2002, 24(8): 1015-1025.

[6] Murtagh P J, Basu B, Broderick B M. Along-wind response of a wind turbine tower with blade coupling subjected to rotationally sampled wind loading[J]. Engineering Structures. 2005, 27(8): 1209-1219.

[7] Murtagh P J, Ghosh A, Basu B, et al. Passive Control of Wind Turbine Vibrations Including Blade/Tower Interaction and Rotationally Sampled Turbulence[J]. Wind Energy. 2008, 11: 305-317.

[8] Spagnoli A, Montanari L. Along-wind simplified analysis of wind turbines through a coupled blade-tower model[J]. Wind and 
Structures. 2013, 17(6): 589-608.

[9] Liu W Y. The vibration analysis of wind turbine blade-cabintower coupling system[J]. Engineering Structures. 2013, 56: 954-957.

[10] Lee D, Hodges D H, Patil M J. Multi-flexible-body Dynamic Analysis of Horizontal Axis Wind Turbines[J]. Wind Energy. 2002, 5(4): 281-300.

[11] Kang N, Chul Park S, Park J, et al. Dynamics of flexible tower-blade and rigid nacelle system: dynamic instability due to their interactions in wind turbine $[\mathrm{J}]$. Journal of Vibration and Control. 2014.

[12] Jonkman J M, Butterfield S, Musial W, et al. Definition of a 5-MW reference wind turbine for offshore system development[M]. National Renewable Energy Laboratory Golden, CO, 2009.

[13] Lindenburg C. Aeroelastic Modelling of the LMH64-5 Blade[M]. Petten, 2002.

[14] Hansen M O L. Aerodynamics of Wind Turbines[EB/OL]. London: Taylor and Francis, 2013. 